\title{
Ciudad rica y ciudadanos pobres. La consideración de la riqueza en el republicanismo florentino
}

\author{
Jesús Luis CASTILLO VEGAS \\ Universidad de Valladolid \\ castillo@der.uva.es
}

\begin{abstract}
RESUMEN
La lectura de los clásicos, el estudio de la historia y la atenta observación de la práctica política de su tiempo le llevarán a Maquiavelo a romper con la tradición humanista sobre la propiedad y a defender la necesidad de limitaciones sobre la misma. Su concepción republicana sobre la propiedad se concentra en el lema de que la ciudad sea rica y los ciudadanos pobres. Esto supone una política de moderación que excluye por igual la concepción oligárquica de quienes confunden la riqueza de la ciudad con la de sus gobernantes; así como el igualitarismo radical de los que niegan con su exclusivismo la existencia de los dos humores (umori) que debidamente coordinados hacen que una república, con un gobierno mixto, sea segura, estable y rica.
\end{abstract}

PALABRAS CLAVE: Maquiavelo, Republicanismo, Riqueza, Corrupción, Pobreza.

\begin{abstract}
Reading the classics, studying history and careful observation of the political practice of time will lead to Machiavelli to break with the humanist tradition on the property and to defend the need for limitations on it. The republican conception of the land is owned by the motto of the city's rich and poor citizens. This is a policy of moderation which excludes alike oligarchic conception of those who confuse the wealth of the city with their rulers, and radical egalitarianism with its exclusiveness denying the existence of the two humors (umori) that make properly coordinated a republic with a mixed government, safe, stable and rich.
\end{abstract}

KEYWORDS: Machiavelli, Republicanism, Wealth, Corruption, Poverty.

\section{Introducción}

Vamos a defender en este trabajo que los representantes del republicanismo florentino, con Maquiavelo a la cabeza, por una parte, continúan las ideas favorables sobre la riqueza que habían sido sostenidas por el humanismo cívico florentino, pero, por otra parte, se apartan de ellas al resaltar los peligros que la riqueza excesiva de los ciudadanos representa para la república. En el siglo XIV la concepción sobre la riqueza propia de la orden franciscana se había extendido por toda Italia. Esta mentalidad franciscana consideraba a la pobreza como la principal de las virtudes y pretendía que no sólo fuera el ideal de la vida religiosa, sino el criterio a seguir por todos los cristianos. El abandono de esta concepción franciscana es obra del humanismo cívico florentino. Se trata de autores que, 
con un gran conocimiento de los clásicos de la Antigüedad, ensalzan la importancia de la riqueza.

No es casual que fueran autores relacionados con Florencia los que encabezan este cambio de rumbo, dado que es una de las ciudades más ricas del momento. Los nuevos humanistas que trabajan para las repúblicas italianas, de manera especial para las pujantes de Florencia y Venecia, están reconciliados con las riquezas de sus ciudadanos. Frente a la primacía de la vita contemplativa, propia de toda la Edad Media, se recupera la importancia de la vida activa, que incluye tanto la vida política como la dedicada a los negocios económicos.

Para humanistas como Coluccio Salutati (1331-1406), la riqueza, además de medio necesario para la práctica de algunas virtudes, es una garantía de la estabilidad del poder. "Coluccio insiste en la idea de que en las ciudades libres el soberano es el pueblo: en Florencia, ciudad de artesanos y mercatores, no de caballeros ni de soldados, ciudad pacífica y laboriosa, gobernaban las artes, y la tiranía debía ser desterrada"1. Los humanistas van a mantener una actitud positiva hacia la riqueza, así lo hace por ejemplo Leonardo Bruni (1370-1444) quien elogia a Florencia por su riqueza. "Abogando por la riqueza, los humanistas censuraban implícitamente la vieja tradición cristiana de pobreza apostólica, la que había encontrado un altavoz institucional con la creación de la orden franciscana en el siglo XIII"2. Si durante la Edad Media la propiedad privada había sido vista como un mal inevitable, este primer renacimiento considera las riquezas como una realidad valiosa. Para Bruni la riqueza, el comercio, el desarrollo artístico de la ciudad eran consecuencias de su gobierno en libertad y así existían en la Florencia de su tiempo y no fueron posibles cuando Roma la mantenía bajo su poder.

El traductor de Aristóteles introduce un interesante giro en la apreciación de la propiedad. No se trata tanto de destacar la importancia de las riquezas para el desarrollo de las virtudes morales privadas, como la importancia que ese elemento tiene para la ciudad. La estimación medieval de la pobreza, que había llegado a los extremos de los fraticelli, es ahora vista con recelo por sus repercusiones sociales y políticas. La rebelión de

\footnotetext{
${ }^{1}$ E. GARIN, Ciencia y vida civil en el renacimiento italiano, versión castellana de Ricardo Pochtar, Madrid, Taurus, 1982, 32-33.

2 J. HANKINS, "El humanismo y los orígenes del pensamiento político moderno", en J. Kraye (ed.), Introducción al bumanismo renacentista, edición española de Carlos Clavería, traducción de Lluís Cabré, Madrid, Cambridge University Press, 1998, 169.
} 
los trabajadores de la lana, en 1378, puso de manifiesto lo fácil que era pasar de la exaltación herética de la pobreza a la persecución física de los más ricos ${ }^{3}$. "De la lucha en contra de los Fraticelli surgió la primera crítica fundamental al ideal de la paupertas"4.

La importancia de Leonardo Bruni en este cambio de rumbo está fuera de toda duda. Su conocimiento de Aristóteles le permitió descubrir los argumentos del peripatético en favor de la propiedad, como base para algunas virtudes (la magnanimidad y la liberalidad), pero también para la propia ciudad que necesita riquezas para mantenerse. Con parecidos argumentos Poggio Bracciolini (1380-1459) y Matteo Palmieri (1406-1475) sostienen la dificultad de llevar a cabo una vida correcta desde la pobreza, defienden la importancia de las riquezas para el desempeño de la actividad política, justifican la riqueza de las ciudades, se preocupan de su correcto emplazamiento para que los ciudadanos tengan suficientes medios de qué vivir y, en los grandes acontecimientos sociales, celebran con gozo la potencia adquirida. La confianza en las posibilidades del hombre se traduce también en la pretensión de que el talento y el esfuerzo sean debidamente recompensados. La exaltación de la riqueza forma parte del goce por la vida que se refleja no solo en los escritos de estos humanistas, sino en las numerosas obras de arte que surgen durante este período.

En términos generales, Maquiavelo seguirá la misma visión positiva hacia la propiedad pero hay algunos cambios decisivos. Uno de ellos es su sorprendente consejo de que el príncipe no debe ser liberal, rompiendo toda una larguísima tradición de los Espejos de príncipes que incluían esa virtud entre las aconsejadas a los gobernantes. La razón de ello es bien conocida, ya que, según Maquiavelo, la liberalidad acabará necesariamente gravando al pueblo con mayores impuestos ${ }^{5}$. A largo plazo, la supuesta virtud de la liberalidad obligará al gobernante a expropiar vorazmente los recursos de los gobernados. Frente a quienes podrían encontrar aquí un precedente de la conocida aversión liberal al incremento de los impuestos, defenderemos el carácter republicano de Maquiavelo que supedita el poder económico -al igual que el militar y el religioso- al soberano poder de la

\footnotetext{
3 Véase A. STELLA, La révolte des Ciompi. Les hommes, les lieux, le travail, París, Éditions de L'École des Hautes Études en Sciences Sociales, 1993.

${ }^{4} \mathrm{H}$. BARON, En busca del humanismo cívico florentino. Ensayos sobre el cambio del pensamiento medieval al moderno, traducción de Miguel Abelardo Camacho Ocampo, México, FCE, 1993, 185.

${ }^{5}$ N. MACHIAVELLI, Il Principe, cap. XVI: "E sarà necessitato alla fine, se si vorrà mantenere el nome del liberale, gravare e populi estraordinariamente ed essere fiscale e fare tutte quelle cose che si possano fare per avere danari”" (Opere, a cura di Mario Bonfantini, Milán, Riccardo Ricciardi Editore, $2^{\mathrm{a}}$ ed., 1963, p. 51).
} 
república. Nuestro trabajo recaerá sobre el lema que propone Maquiavelo para organizar correctamente las riquezas de la ciudad, a saber, el de que "la ciudad sea rica y los ciudadanos pobres". Maquiavelo comparte con el humanismo cívico el objetivo de que la ciudad sea rica, pero se aparta de esa tradición cuando, plenamente conforme con las exigencias del republicanismo clásico, sostiene que es preferible que los ciudadanos sean pobres. Percibe los peligros que unos ciudadanos ricos pueden ocasionar al conjunto de la ciudad. La república sólo puede sobrevivir si hay moderación de riquezas, si no hay ciudadanos particulares tan ricos que puedan tener dominación sobre otros hombres. Por una parte, la ciudad pobre no se podrá conservar segura durante largo tiempo, ni podrá mantener muchos ciudadanos y por ello tampoco muchos soldados. Pero, por otra, para Maquiavelo una ciudad no se convierte en rica por el mero hecho de que lo sean sus ciudadanos, lo que le aleja definitivamente de la perspectiva liberal.

Podría pensarse que la visión enteramente positiva sobre la propiedad, mantenida por el humanismo cívico, ya había sido abandonada antes de que lo hiciera Maquiavelo por personajes como Girolamo Savonarola (1452-1498), a quien se identifica de manera muy relevante con las quemas de artículos de lujo en la ciudad de Florencia. El dominico Savonarola había predicado sermones incendiarios contra los Médici desde San Marcos y había hecho algunas profecías que le ganaron el favor popular antes de morir quemado en la hoguera. Entre las actividades atribuidas al fundamentalismo de Savonarola está la de haber organizado grupos de adolescentes, "con modos propios de la disciplina religiosa o paramilitar", que recorrían las calles de Florencia al grito de "Viva Cristo Rey"6. Sin embargo, no hay en Savonarola un rechazo de la riqueza, ni siquiera de la riqueza excesiva, sino de la inmoralidad que asociaba a cierto tipo de riqueza (pinturas, aceites, pelucas, etc.). Lo cierto es que Savonarola "se había mostrado bien dispuesto a apoyar la suposición de los anteriores humanistas 'cívicos' de que la gran riqueza había de considerarse como prueba de su especial excelencia" 7 . Savonarola, que apoyó iniciativas de origen franciscano como la creación de un Monte de Piedad para ayudar a los pobres, sigue pensando que el buen gobierno es recompensado por Dios con la riqueza, "porque no habiendo gastos superfluos se acumularía en el erario público un inmenso tesoro con

${ }^{6}$ F. FERNÁNDEZ BUEY, "Introducción”, en G. Savonarola, Tratado sobre la república de Florencia y otros escritos, traducción de Juan Manuel Forte, Madrid, Los Libros de la Catarata, 2000, 33.

${ }^{7}$ Q. SKINNER, Los fundamentos del pensamiento politico moderno, I. El renacimiento, traducción de Juan José Utrilla, México, FCE, 1985, 187. 
el que se confortaría a los pobres y se podría pagar con facilidad a los soldados y oficiales, de modo que los enemigos de la ciudad la mirarían con temor"'. Contrariamente a las tesis que defenderá Maquiavelo, se opone a una limitación legal de las riquezas ya que las considera como una muestra del favor divino. ¿Qué hará cambiar esa opinión irrestrictamente favorable sobre la riqueza a pensadores como Maquiavelo o Giannotti? Sin duda influyó la propia historia política de Florencia y la persistente presencia de familias como los Médici en su gobierno, y de manera muy concreta la vuelta de éstos en 1512, ya que su acceso al poder era incomprensible sin la gran riqueza de esta familia.

Así y todo, no hay en Maquiavelo ningún rechazo global a la propiedad. La considera plenamente justificada pero censurará los excesos de la misma en la medida en que perjudican a la ciudad. Cuando Maquiavelo compara los gobiernos de los mejores emperadores romanos con los peores, describe los primeros como aquellos en que hay seguridad, paz, justicia, y también como aquéllos donde "los ciudadanos ricos gozan de sus riquezas" . Sobre esta misma materia señala Renaudet: "Maquiavelo se entendería con los constituyentes para reconocer en la propiedad un derecho inviolable y sagrado. No tiene nada de común ni con los franciscanos espirituales ni con los taboritas"10. Es cierto que Maquiavelo justifica la propiedad pero, a la vez, promueve una legislación que defienda a los hombres de esa natural apetencia de bienes que los arrastra hacia la corrupción y de los peligros que la riqueza excesiva puede suponer especialmente para la forma de gobierno republicana.

\section{El ideal republicano sobre la propiedad}

Por lo que a la república ideal se refiere, ésta es siempre para Maquiavelo la más segura. La inestabilidad es una condición constitutiva de todas las instituciones humanas. No se puede evitar aunque sí aminorar. En sus escritos Maquiavelo expone diversos recursos para hacer frente a la inestabilidad característica del mundo político. Para luchar contra ella concibe Maquiavelo básicamente tres instrumentos: el gobierno mixto, la milicia

\footnotetext{
${ }^{8}$ SAVONAROLA, Tratado sobre la república de Florencia, lib. II, 81.

${ }^{9}$ MACHIAVELLI, Discorsi sopra la prima deca di Tito Livio, I, cap. 10: "Vedrà il Senato con la sua autorità, i magistrati co'suoi onori, godersi i cittadini ricchi le loro ricchezze" (Opere, a cura di Mario Bonfantini, Milán, Riccardo Ricciardi Editore, $2^{\mathrm{a}}$ ed., 1963, p. 121).

10 A. RENAUdeT, Maquiavelo, traducción de Francisco Díez del Corraly Daniele Lacascade, Madrid, Tecnos, 1965, p. 214.
} 
nacional y la limitación de la propiedad. De la adecuación del gobierno mixto para hacer frente a la anaciclosis, o inevitable evolución que somete a todos los regímenes políticos a un recorrido circular, así como de la eficacia de la milicia para garantizar la seguridad frente a las apetencias de los países vecinos ya nos hemos ocupado en otra ocasión ${ }^{11}$. Ahora nos interesa ver cómo para Maquiavelo el exceso de riqueza de los ciudadanos lleva a la corrupción. "Per lui, la storia dimostra come la ricchezza sproporzionata di alcuni cittadini sia pericolosa anche alla forma piú libera di costituzione e possa condurre alla distruzione della libertà"12. Nos centraremos en considerar cuál es el papel que la propiedad ocupa como factor de corrupción, y por lo tanto de la inestabilidad política que el Estado debe evitar.

La reflexión sobre la propiedad en Maquiavelo debe tomar como punto de partida las pesimistas consideraciones que hace el autor florentino sobre la naturaleza humana. La necesaria regulación de los bienes deberá tener muy presente la tendencia natural a la pereza y a la codicia propia de todos los seres humanos. Maquiavelo es plenamente consciente no solo de la posibilidad de la corrupción, sino de la alta probabilidad de la misma dada la condición de la naturaleza humana. Su pesimismo antropológico se muestra en las aceradas recomendaciones de El príncipe cuando insiste en que, si el gobernante ha tenido que derramar la sangre de alguien, por nada del mundo se apodere de los bienes de la víctima, "porque los hombres olvidan más pronto la muerte de un padre que la pérdida de su patrimonio"13. Consciente de la importancia que los hombres atribuyen a la propiedad recomienda a los gobernantes que lo tengan muy en cuenta para estimular al soldado en la lucha $y$, por ello, insiste en que no se permita al soldado que envíe a su casa nada de lo que posee, ni que lo ponga a resguardo en ninguna parte, “de esa forma, el presunto desertor se convencerá de que, huyendo tal vez salve la vida, pero que en ningún caso conservará el botín, que muy a menudo aprecia y defiende tanto o más que a su propia vida"14.

\footnotetext{
11 Véase J. L. CASTILLO VEGAS, "Libertad y participación ciudadana en el republicanismo florentino", Revista Tachirense de Derecho, 15 (2003), 57-82; J. L. CASTILLO VEGAS., "Ciudadanía y milicia en el republicanismo florentino", en Tópicos. Revista de Filosofía, 37 (2009), 135-160.

${ }^{12}$ U. DOTTI, Niccolò Machiavelli. La fenomenologia del potere, Milán, Feltrinelli Sditore, 1979, 113.

${ }^{13}$ N. MACHIAVELLI, Il Principe, cap. XVII: "Ma sopra tutto astenersi dalla roba d'altri; perché li uomini sdimenticano più presto la morte del padre che la perdita del patrimonio" (Opere, 54-55).

${ }^{14}$ MAQUIAVELO, Del arte de la guerra, lib. IV, traducción e introducción de Fernando Puell de la Villa, Madrid, Minerva Ediciones, 2009, 219.
} 
Maquiavelo expone el lema que debe orientar el tratamiento adecuado de la riqueza ("ciudad rica y ciudadanos pobres") analizando los efectos que tuvieron en Roma las leyes agrarias. Cuando el pueblo romano no se conformó con la igualdad política, sino que quiso la distribución de la propiedad, entonces empezó el fin de la república. Insiste en cómo la conocida revolución de los hermanos Graco fue el principio que llevó a la desintegración de la república romana. Las leyes agrarias limitaban la cantidad de tierras que un mismo ciudadano podía poseer y, sobre todo, obligaban a que los campos despojados al enemigo fueran repartidos entre el pueblo romano. Maquiavelo no criticará tanto el contenido de estas leyes como el modo en que se ejecutaron, con mucho retraso y con efectos retroactivos. Maquiavelo, según G. Bock, más que los fines (división de la propiedad, limitación de los latifundios) rechazaría los métodos empleados (violencia, leyes retroactivas) $)^{15}$. La ejecución de las leyes agrarias de los Graco estaría en contradicción con lo que será la máxima de Maquiavelo en esta materia, a saber, hacer que la ciudad sea rica y los ciudadanos pobres, porque producen justamente el efecto contrario. Esas leyes empobrecen el erario público y hacen ricos a algunos ciudadanos. Pero lo peor de todo es que esa reforma "arruinó por completo la libertad romana", ya que provocó la guerra civil entre la nobleza y el pueblo que daría lugar finalmente al principado de Julio César. Si la tensión política entre nobleza y pueblo había sido un instrumento básico para lograr unas leyes favorables para todos, sin embargo, al crear cada una de las facciones su propio ejército, se originó el fin de la república romana. La nobleza de Roma, que había cedido a la hora de crear los tribunos de la plebe, no lo hizo cuando se trató de repartir las riquezas, "porque los hombres estiman más las riquezas que los honores"16.

Para evitar la aparición de las divisiones verticales o sectas (fazioni, sètte), en el interior de la república, un remedio adecuado consiste en tener siempre, como lo hizo Roma, una guerra en el exterior. Pero la otra solución que propone Maquiavelo es “mantener a los ciudadanos en la pobreza, para que las riquezas desprovistas de virtud no puedan corromper ni a sus poseedores ni a los demás"17. Se garantiza seguridad al

\footnotetext{
${ }^{15}$ Véase G. BOCK, "Civil discord in Machiavelli's Istorie Fiorentine", en G. Bock y otros (eds.), Macbiavelli and Republicanism, Cambridge U. P., 1990, 192.

${ }^{16}$ Discorsi, I, 37: "Quanto gli uomini stimano più la roba che gli onor" (Opere, 173).

17 Discorsi, III, 16: "L'uno mantenere i cittadini poveri, acciocché con le ricchezze sanza virtù e' non potessino corrompere né loro né altri”" (Opere, 361).
} 
ciudadano para que disfrute el fruto de su trabajo, frente a la apropiación ilimitada y arbitraria que el tirano puede llevar a cabo, pero para Maquiavelo la propiedad excesiva es un grave peligro para la república. Mucha riqueza privada arruina la ciudad, corrompe sus instituciones; y, además, degrada a sus ciudadanos, les envilece. La idealización de la república romana no alcanza sólo a la forma de gobierno -la república frente a la monarquía-, ni a la organización del ejército -los ciudadanos soldados frente al sistema entonces vigente de los condottieri-, sino también a las costumbres domésticas de los mismos ciudadanos. Se admira la frugalidad de la Roma republicana, la austeridad extrema de sus habitantes. Dice Maquiavelo que los romanos daban a cada colonia que establecían una pequeña porción de terreno, ya que "viviendo austeramente en casa, no era razonable que quisieran que sus hombres nadasen en la abundancia fuera de ella"18.

Para estos autores florentinos, no sólo para Maquiavelo, "uno de los mayores peligros para el mantenimiento de la libertad y la virtud pública lo constituye una devoción excesiva a la búsqueda de la riqueza privada"19. La ciudad necesita ciudadanos dispuestos a sacrificarse por ella y no exclusivamente preocupados por su personal enriquecimiento.

Para Maquiavelo la riqueza puede afectar negativamente al desarrollo de las virtudes cívicas. La extensa reflexión de Maquiavelo sobre la virtud (virtü) rompe con la tradición estoica y cristiana en varios sentidos. En un aspecto importante, señala Skinner, cómo, a diferencia de Cicerón, se excluye toda consideración sobre la justicia para centrarse en las otras tres virtudes cardinales ${ }^{20}$. "Para servir al Estado el ciudadano necesita valentía, prudencia y templanza. El ciudadano debe ser valiente en la guerra, prudente en los negocios públicos y recomienda moderación en la riqueza y costumbres"21. Si es difícil que los ricos entren en el reino de los cielos, no lo es menos que sean buenos ciudadanos en la república.

\footnotetext{
${ }_{18}$ Discorsi, II, cap. 7: "Dipoi perché vivendo loro poveri a casa, non era ragionevole che volessono che i loro uomini abbondassino troppo fuora" (Opere, 239).

${ }^{19}$ Q. SKINNER, Los fundamentos del pensamiento politico moderno, I. El renacimiento, traducción de Juan José Utrilla, México, FCE, 1985, 187.

${ }^{20}$ Q. SKINNER, "La idea de libertad negativa: perspectivas filosóficas e históricas", en R. Rorty y otros (compls.), La Filosofía en la Historia, trad. de Eduardo Sinnatt, Barcelona, Paidós, 1990, 252.

${ }^{21} \mathrm{~J}$. L. CASTILLO VEGAS, "Fortuna, virtù y gloria. Consideraciones sobre la moral republicana de Maquiavelo", Praxis Filosófica, 26 (Enero-Junio 2008), 102.
} 


\section{Que la ciudad sea rica}

Una ciudad rica no es una ciudad cuyos gobernantes tengan muchas riquezas. Si nos fijamos en las relaciones entre los diferentes pueblos, el que uno de sus gobiernos sea demasiado rico puede convertirse incluso en un grave problema, porque es inevitable que acabe atrayendo la codicia de los vecinos, como la inmensa riqueza de Darío provocó la perdición de su reino ${ }^{22}$. Maquiavelo analiza cómo las conquistas, si la ciudad no está bien ordenada, pueden acabar llevándola a la ruina. La conquista de otros países es a veces una necesidad inevitable, una cuestión de supervivencia, y la ciudad debe estar organizada para hacer frente a esa contingencia. La fórmula es, dejando aparte el establecimiento de un régimen político republicano y la organización militar basada en los ciudadanos y no en mercenarios, por lo que se refiere a la riqueza, la de "mantener el erario rico y a los particulares pobres" (“tenere ricco il publico, povero il privato") ${ }^{23}$. No hay ningún elogio de la conquista por sí misma. Si se pudiera vivir sin ella, como felizmente les sucede a las ciudades alemanas que describe Maquiavelo, sería mucho mejor, pero no siempre es así y, a veces, la expansión territorial es una necesidad. Lo importante en este caso es que la expansión no acabe arruinando al país conquistador. Lo fundamental no es adquirir territorios sino poder. Al conseguir bienes nuevos, tanto a nivel individual como colectivo, podemos enriquecer o empobrecer. A Florencia le empobreció apoderarse de la Toscana y lo mismo le sucedió a Venecia al controlar la Lombardía. Como es sabido, Maquiavelo somete las guerras al examen utilitarista de las consecuencias. ¿Para qué ha servido la guerra? No se pregunta si era o no justa, sino si la guerra enriqueció o empobreció la ciudad, si la expansión territorial hace más segura o más inestable la república. Por eso se pueden producir múltiples paradojas, como ganar la guerra y perder el reino (Pirro), o perder la guerra y ganar la paz (como hace frecuentemente Venecia según Maquiavelo-, ya que sabe negociar con mucha habilidad incluso cuando ha sido derrotada). No siempre tener más territorio supone tener más seguridad y estabilidad. También es posible que la conquista sea el desencadenante de la corrupción como en la famosa toma de la apacible Capua, tanto para los romanos como para los soldados de

\footnotetext{
22 Criticando la extendida opinión de que el dinero es el nervio de la guerra, se refiere Maquiavelo a Darío para recordar que su enorme tesoro no fue suficiente para defenderle de Alejandro (Discorsi, II, 10, 244).

${ }^{23}$ Discorsi, II, 19 (Opere, 271).
} 
Aníbal ${ }^{24}$. Una mayor riqueza puede ir unida a mayores vicios, y la fertilidad de la tierra puede acabar convirtiendo a los hombres en débiles y carentes de virtù.

Maquiavelo analiza la relación entre la riqueza y la forma de gobierno y llega a la conclusión de que, mientras la república hace más ricas a las ciudades, la monarquía y la aristocracia sólo enriquecen a los propios gobernantes. Es el vivere libero lo que beneficia a la ciudad: "porque se ve por experiencia que las ciudades nunca aumentan su dominio ni su riqueza sino cuando viven en libertad" 25 . Roma se hace rica, extiende su población y sus territorios cuando se libra de los reyes. Maquiavelo explica así esta conexión: "La causa es fácil de entender: porque lo que hace grandes las ciudades no es el bien particular, sino el bien común" ("Perché non il bene particulare ma il bene comune è quello che fa grandi le città' ${ }^{26}$. En cambio, los príncipes, con sus intereses antagónicos al común, se ven obligados para conservar su poder a reducir la riqueza de la ciudad. De este modo, para Maquiavelo, la pérdida de la libertad va siempre unida a otro grave mal, a saber, a la pobreza. Las ciudades libres prosperan, las que no tienen libertad política empobrecen.

Hay en Maquiavelo una defensa de la república como la forma de gobierno que proporciona mayor riqueza. Los ciudadanos que viven libres tienen más hijos y trabajan más, porque no temen que les sea arrebatado su patrimonio. "Las riquezas se multiplican en mayor número, tanto las que provienen de la agricultura como las que proceden de las artes, pues cada uno se afana gustosamente y trata de adquirir bienes que, una vez logrados, está seguro de poder gozar" 27 . Muy otra es la situación de la tiranía en la que nadie tiene nada seguro. La república garantiza el disfrute de los derechos con sus leyes, frente al sometimiento personal que impone la tiranía. Mientras que para los tiranos es contraproducente enriquecer a los ciudadanos, por virtuosos que sean, la república sería más generosa en recompensar los méritos. Hablando de la ingratitud dice Maquiavelo:

\footnotetext{
${ }^{24}$ Discorsi, II, 19, 273.

${ }^{25}$ Discorsi, II, 2: "Perché si vede per esperienza le cittadi non avere mai ampliato né di dominio né di ricchezza se non mentre sono state in libertà" (Opere, 225). Una de las ventajas de la vida en libertad es la de poder gozar de los bienes sin temor, "potere godere liberamente le cose sue sanza alcuno sospetto" (Discorsi, I, 16, 135).

26 Discorsi, II, 2, 225.

27 Discorsi, II, 2: "Perché ciascuno volentieri multiplica in quella cosa e cerca di acquistare quei beni che crede acquistati potersi godere” (Opere, 229).
} 
"vemos que los pueblos nunca incurren en ella por avaricia, y por sospecha lo hacen en menos ocasiones que los príncipes, teniendo menos causa para recelar"28.

La defensa de la república en Maquiavelo incluye múltiples argumentos. Además de ser el gobierno más libre y más seguro, es también el que permite una mayor riqueza a las ciudades. Las ciudades donde gobierna el pueblo progresan rápidamente. Están más pobladas y ricas y hay más libertad para expresarse y para crear obras de arte. Bajo los gobiernos republicanos las ciudades son ricas, tienen mucha población y viven seguras; bajo las tiranías solamente son ricos sus gobernantes. En resumen, no hay ciudad rica sin gobierno republicano.

\section{Que los ciudadanos sean pobres}

Señala Maquiavelo que las repúblicas bien organizadas deben mantener el erario público rico y a los ciudadanos pobres: "E perché le republiche bene ordinate hanno a tenere rico il publico e gli loro cittadini pover"' 29 . Ya hemos visto que una ciudad rica es una ciudad con muchos ciudadanos, capaz de alimentar una gran población y por ello capaz de dotarse de los soldados que necesita para su defensa. Ha llegado el momento de examinar el otro aspecto de su tesis, a saber, la preferencia por los ciudadanos pobres.

El aprecio republicano por la pobreza no es exclusivo de Maquiavelo pero está muy acentuado en este autor. Maquiavelo recela de la riqueza excesiva, de la ociosidad y cobardía que acompañan a aquélla. Por eso, aunque prefiere que la ciudad se funde en un lugar próspero, propone que las leyes sean tales que obliguen a los ciudadanos a vivir de manera austera: "Afirmo, pues, que es más prudente elección establecerse en lugares fértiles, siempre que esa fertilidad se reduzca a los debidos límites mediante las leyes"30. Ahora bien, ¿no será inevitable que los ciudadanos sean ricos si lo es la ciudad? Es evidente que hay una cierta tensión en su dictum de que "las repúblicas bien organizadas deben mantener el erario público rico y a los ciudadanos pobres", por lo que habrá que intervenir, mediante las leyes, para conseguir a la vez ambos objetivos. Si la fertilidad del

\footnotetext{
${ }^{28}$ Discorsi, I, 29, 158.

${ }_{29}$ Discorsi, I, 37, 171. La importancia de este principio queda resaltada porque vuelve a reproducirlo después en Discorsi, III, 25: "Noi abbiamo ragionato altrove, como la più utile cosa che si ordini in uno vivere libero è che si mantenghino i cittadini poveri" (Opere, 378).

30 Discorsi, I, 1: "Dico adunque essere più prudente elezione porsi in luogo fertile, quando quella fertilità con le leggi infra debiti termini si ristringa" (Opere, 94).
} 
suelo, la proximidad del mar, la cercanía de un gran río, etc., son todos factores que ayudan a enriquecer a la ciudad, habrá que evitar mediante la legislación que los ciudadanos se vuelvan, a la vez que ricos, cobardes y perezosos. Es la ciudad la que debe ser rica y no los ciudadanos, porque de lo contrario, la inestabilidad está asegurada. Maquiavelo explica con un ejemplo la posibilidad de conjugar ambos términos: los antiguos egipcios podían vivir plácidamente del fertilísimo Nilo, pero una severa disciplina hacía valientes a sus soldados.

Que los ciudadanos sean pobres no es una propuesta para hacerlos a todos igualmente miserables. La república, la forma de gobierno más segura y estable, precisará como cimiento imprescindible una cierta igualdad y ésta se rompe tanto por la aparición de algunos personajes tan ricos que pueden evitar que les alcancen las leyes, como si el gobierno popular utiliza toda clase de medios para repartir los bienes de los más ricos. "Maquiavelo ha visto claramente, e insiste enérgicamente en ello, que la principal tara del gobierno de la multitud es su igualitarismo mal comprendido y agresivo, la envidia democrática, que tiende a nivelar todas las superioridades"31. Ambos peligros deben ser conjurados. No se debe buscar en el planteamiento de Maquiavelo una defensa del igualitarismo extremo. De hecho critica en su Historia de Florencia la revuelta de los Ciompi cuyo contenido revolucionario se expresa con la afirmación de uno de los trabajadores de la lana:

Si nos quedáramos todos completamente desnudos, veríais que somos iguales a ellos; que nos vistan a nosotros con sus trajes y a ellos con los nuestros y, sin duda alguna, nosotros pareceremos nobles y ellos los plebeyos; porque son sólo la pobreza y las riquezas las que nos hacen desiguales ${ }^{32}$.

Para Maquiavelo los Ciompi no querían la igualdad de los cargos para todos, sino que pretendían excluir de los mismos a la nobleza, mucho más que otros gobiernos populares anteriores ${ }^{33}$, lo que conducía a los nobles o bien al exilio o a la indignidad de la

\footnotetext{
${ }^{31}$ P. MESNARD, El desarrollo de la filosofía politica en el siglo XVI, trad. de Jorge Renales Fernández, México, Ediciones de la Universidad de Puerto Rico, 1956, 43.

${ }^{32}$ N. MAQUIAVELO, Historia de Florencia, III, 13. Citamos esta obra por la edición, traducción y notas de Félix Fernández Murga, Madrid, Tecnos, 2009, 161.

33 Véase J. M. NAJEMY, “Civic humanism and Florentine politics”, en Jame Hankins (ed.), Renaissance civic bumanism. Reappraisals and Reflections, Cambridge, Cambridge University Press, 2000, 83.
} 
exclusión, circunstancias ambas que acabaron creando el ambiente propicio para la vuelta al poder de los Médici.

Hay otro ejemplo interesante que ayuda a entender cómo se aleja el republicanismo de Maquiavelo de estas medidas populistas. Cuando se introduce el "catastro" en Florencia, en 1427, como registro para llevar a cabo una imposición proporcional, el partido popular no se conforma con esto sino que pretende aplicar la medida retroactivamente ${ }^{34}$. Maquiavelo, que rechaza las medidas retroactivas ya que "para una república no puede haber ley más nefasta que la que pretende retrotraerse a tiempos ya pasados" 35 , considera que esas medidas debilitan a la ciudad. Esa medida populista se aleja del ideal de la república romana que no destierra a sus ciudadanos sino que atrae población, a los pobres con un fácil acceso a la ciudadanía y a los cargos públicos, y a los ricos permitiéndoles el pacífico disfrute de su propiedad. Cuando Maquiavelo habla de pueblo hay que entenderlo en el sentido que se usaba entonces en la literatura política renacentista. "El léxico de la época se encarga de diferenciar entre 'plebe', la masa trabajadora que vivía en condiciones miserables y sin derechos, y 'pueblo', los ciudadanos con un oficio y de pleno derecho"36. El pueblo son las clases medias, que forman parte de los diversos gremios de la ciudad, que pagan impuestos, que participan de los cargos públicos y gozan de plenos derechos. En cambio, la plebe la forman los asalariados, los criados, los proletarios. Las propuestas políticas de Maquiavelo son más para el pueblo que para la plebe.

El aprecio que siente por la pobreza tiene un límite claro. La pobreza no debe ser tan grande que impida a algún ciudadano participar de los cargos públicos. Así, en Roma, la pobreza "no impedía el acceso a ningún cargo ni a ningún honor, sino que se iba a buscar la virtud allí donde habitase, y ese modo de vida hacía menos deseables las riquezas"37. Maquiavelo se emociona ante personajes como Cincinato que estaba arando sus campos cuando es llamado a desempeñar la dictadura y no sólo es capaz de renunciar al poder una vez cumplida su misión, sino que vivía “con cuatro yugadas de tierra". El mismo elogio muestra respecto a Lucio Tarquinio, que era tan pobre que, aunque era el

\footnotetext{
34 MAQUIAVELO, Historia de Florencia, IV, 14, 205.

35 Ibidem, III, 3, 144.

${ }^{36}$ J. E. ABAD BAENA, Las cenizas de Maquiavelo, Granada, Comares, 2008, 50.

37 Discorsi, III, 25: "Che vedere come per la povertà non ti era impedita la via a qualunque grado ed a qualunque onore, e como e'si andava a trovare la virtà in qualunque casa l'abitasse” (Opere, 378).
} 
jefe de la caballería de Cincinato, peleaba a pie, "il quale per la povertà militava a piede" 38 . Son éstos los héroes de Maquiavelo quienes no sólo dan ejemplos de valor cívico y militar, sino que saben mantenerse pobres, conformarse con el honor que ganan en la guerra, y dejar las riquezas al erario público ${ }^{39}$.

Se elogia la república romana precisamente porque en ella también los ciudadanos pobres podían acceder a los cargos públicos. Si la pobreza no impide el acceso a las magistraturas entonces las riquezas ya no son tan deseables. En cambio, cuando los cargos se obtienen por medios privados (riqueza, reputación, amigos), entonces la república está perdida. El gobierno republicano se caracteriza por la ruptura de la conexión automática entre poder y riqueza. En la república correcta ni la riqueza es un medio suficiente para llegar al poder, ni el ejercicio del poder es un instrumento para facilitar el enriquecimiento privado. Una república bien constituida premia a quien busca reputación mediante medios públicos, como los famosos triunfos que Roma concedía a los generales victoriosos; pero, igualmente, actúa con toda energía contra quienes procuran la reputación mediante medios privados, prestando dinero, proporcionando dotes (incluso repartiendo trigo a los pobres como recoge Maquiavelo con el ejemplo de Spurio Melio), y todo ello para hacer retornar a los límites a quien los había sobrepasado $^{40}$. La propiedad encuentra así un límite claro en el pensamiento de Maquiavelo: no debe servir para adquirir reputación política. Cuando un ciudadano, mediante sus enormes riquezas, es capaz de conseguir partidarios, se puede convertir en una amenaza para la república porque, en una república bien constituida, no debe ser posible hacer el mal "bajo la sombra del bien" 41 . Según Maquiavelo se pueden dar muchos ejemplos de esta forma de proceder pero prefiere elegir el de Cosme el Viejo, al que la casa de los Médici debe el principio de su grandeza ${ }^{42}$.

Maquiavelo cree positivas las tensiones que existen entre la nobleza y el pueblo, pero no las grandes desigualdades, ni mucho menos considera republicano el espíritu de aquel que vive para incrementar sus riquezas. Para Maquiavelo la búsqueda de la riqueza como principal interés amenaza directamente la libertad republicana. Si el hombre busca,

\footnotetext{
38 Discorsi, III, 25, 378.

39 Discorsi, III, 25: 'L'una la porvertà, e come vi stavano dentro contenti, e come e' bastava a quelli cittadini trarre della guerra onore, e l'utile tutto lasciavano al publico" (Opere, 379).

${ }^{40}$ Discorsi, III, 28, 384.

${ }^{41}$ Discorsi, I, 46, 188.

${ }^{42}$ Discorsi, I, 33, 164.
} 
por encima de todo, la riqueza, entonces ¿cómo pedirle que sea capaz de dar la vida por su patria? El principal motor del ciudadano republicano ha de ser la virtud, la búsqueda del honor y la gloria pero nunca la riqueza.

Maquiavelo declara que la 'riqueza sin dignidad' es, invariablemente, causa de corrupción cívica, y añade que fácilmente podría 'explayarse sobre las ventajas de la pobreza sobre la riqueza', y sobre 'cómo la pobreza da honor a las ciudades', mientras que 'lo otro las ha arruinado', pero esto ya 'ha sido hecho muy a menudo por otros ${ }^{43}$.

El republicanismo no es, sin más, incompatible con toda clase de desigualdad entre los ciudadanos. Como señala Ángel Rivero:

la tradición republicana se organiza básicamente sobre la desigualdad: una primera entre los ciudadanos, hombres libres, y el resto de las personas, donde la política como actividad queda reservada para los primeros. Y una segunda desigualdad, en el propio seno de los ciudadanos, que los hace mayores o menores en dignidad, en riquezas y en linaje. El diseño constitucional de la tradición republicana intentará articular funcionalmente esta desigualdad para salvaguardar la estabilidad de la república y éste será su legado más permanente ${ }^{44}$.

Ahora bien, aunque el republicanismo transige con algunas desigualdades, es totalmente incompatible con otras. Rousseau, ávido lector de Maquiavelo, expondrá con toda rotundidad algunos de estos límites: que ningún ciudadano sea tan rico como para poder comprar a otro ni tan pobre que se vea obligado a vender su voto 45 .

Como ya había señalado Aristóteles en su Política, la principal fuente de las sediciones tiene su causa en la soberbia de los ricos y en la envidia de los pobres ${ }^{46}$. La división económica aparece como el principal factor estructurador de toda ciudad. Esa tensión es inevitable y queda recogida en las principales obras de Maquiavelo: "En todas las ciudades existen estos dos tipos de humores; que nacen del hecho de que el pueblo no

${ }^{43}$ Q. SKINNER, Los fundamentos del pensamiento politico moderno, I, 188.

44 Á. RIVERO, "Republicanismo y neo-republicanismo", Isegoría. Revista de Filosofia Moral y Política, 33 (2005), 12.

45 Véase J.-J. ROUSSEAU, Du Contrat social, lib. II, cap. XI, en Oeuvres Complètes, París, 1964, III, 391-2.

${ }^{46}$ Véase ARISTÓTELES, Politica, IV, 11, 1295 b 1-13. 
desea ser dominado ni oprimido por los grandes y en cambio los grandes desean dominar y oprimir al pueblo" 47 . Un régimen político que no deje dominar de manera excluyente a ninguno de estos dos grupos sociales logrará según Maquiavelo la mayor permanencia.

La solución --arguye Maquiavelo-, consiste en ajustar las leyes constitucionales de modo que se produzca un equilibrio entre estas fuerzas sociales opuestas, un equilibrio en el que todas las partes se vean comprometidas en los negocios del gobierno, y cada una 'vigile a la otra' a fin de prevenir tanto 'la arrogancia de los ricos' como el 'libertinaje del pueblo $^{48}$.

Estamos ante una de las afirmaciones más conocidas y fundamentales del pensamiento político de Maquiavelo:

Las graves y lógicas rivalidades que hay entre las gentes del pueblo y los nobles, nacidas del hecho de que éstos quieren mandar y aquéllos no quieren obedecer, son la causa de todos los males que surgen en las ciudades, ya que todas las demás cosas que perturban la paz de las repúblicas se nutren de esta diversidad de sentimientos ${ }^{49}$.

Esta tensión es inevitable pero, según Maquiavelo, puede ser encauzada correctamente mediante las instituciones para ponerla al servicio del bien común. Esto es la que sucedió en Roma con la creación de instituciones políticas que daban representación tanto al pueblo (los tribunos) como a los nobles (cónsules y Senado). Pero si no se da esa canalización institucional entonces las divisiones acaban con la ciudad, como habría sido el caso de Florencia, según Maquiavelo:

Porque las rivalidades que hubo al principio en Roma entre el pueblo y los nobles acabaron en meras discusiones, mientras que en Florencia acabaron en peleas; las de Roma terminaban con una ley, las de Florencia con el destierro y con la muerte de muchos ciudadanos; las de Roma acrecentaron el valor militar, las de Florencia lo apagaron totalmente; las de Roma llevaron a aquella ciudad, de una igualdad entre sus

\footnotetext{
${ }^{47}$ N. MACHIAVELLI, Il Principe, cap. IX: "Perché in ogni città si truovono questi dua umori diversi; e nasce da questo, che il populo desidera non essere comandato né oppresso da' grandi, e li grandi desiderano comandare e opprimere el populo" (Opere, 32).

${ }^{48}$ Q. SKINNER, Maquiavelo, traducción de Manuel Benavides, Madrid, Alianza, 1984, 85.

${ }^{49}$ MAQUIAVELO, Historia de Florencia, III, 1, 141.
} 
ciudadanos, a una gran desigualdad; las de Florencia la han llevado de la desigualdad a una increíble igualdad ${ }^{50}$.

Las desigualdades entre pueblo y nobleza son inevitables pero deben ser correctamente tratadas para que de ellas deriven buenas leyes (por la tensión entre los contendientes políticos se puede lograr que una ley sirva al bien común), y para que se fortalezca la ciudad (el ejército romano era más potente porque permitía incorporar tanto a los nobles como al pueblo).

Los plebeyos romanos lograron poco a poco el acceso a las diversas magistraturas. Sin embargo, el pueblo florentino no quería solamente participar de los cargos políticos, sino ocupar él solo todo el poder. Para Maquiavelo es más seguro un gobierno mixto en el que participen todas las clases sociales, aunque hace del pueblo el vigilante último de la soberanía. Como la pretensión igualitaria de los florentinos, especialmente durante la revuelta de los Ciompi, era la de un gobierno exclusivo del pueblo, Florencia acabó desbordada en sangre y debilitada por los exilios. "En cambio, en Florencia, cuando el pueblo salía vencedor, privaba a los nobles de las magistraturas, y éstos, cuando trataban de recobrarlas, se veían precisados, no sólo a ser, sino incluso a parecer, iguales a los del pueblo en su sentir y en su modo de vivir" 51 . De este modo explica Maquiavelo la pérdida del valor guerrero en Florencia. El pueblo no tiene valor y la nobleza está debilitada. La igualdad que propugna Maquiavelo, insiste Bock, no es económica o social, sino legal y política $^{52}$. Se trata de reducir los privilegios, de atenerse a las mismas leyes y, sobre todo, de permitir el acceso a los cargos públicos. En esta concepción republicana se recela de las grandes fortunas porque éstas pueden hacer que los cargos públicos se repartan desigualmente.

La corrupción es la subversión del bien común por el interés particular, y la riqueza, aunque no es el único instrumento corruptor, sí es el más extendido. Por eso, la riqueza es una amenaza para el bien común, exactamente desde el momento en que es tan grande que permite a su titular adquirir partidarios, comprar votos, amañar leyes y corromper magistrados. Pero para Maquiavelo esa corrupción es mucho más difícil que se dé en una forma de gobierno republicana, porque, como ya hemos dicho, lo que hace

\footnotetext{
${ }^{50}$ Ibidem.

${ }^{51}$ Ibidem, 142.

${ }^{52}$ G. BOCK, "Civil discord in Machiavelli's Istorie Fiorentine", 189. 
grandes las ciudades no es el bien particular, sino el bien común, y, sin duda, este bien común no se logra más que en las repúblicas: "E sanza dubio questo bene comune non è osservato se non nelle republiche" 53 .

La corrupción es mucho más difícil en las repúblicas porque éstas se asientan en una relativa igualdad de los ciudadanos. Más concretamente, la corrupción va asociada a la desigualdad de riqueza que conlleva superioridad sobre las personas, como es el caso de los gentileshombres, gentiluomini, y en general de todos aquellos "que están ociosos y viven de las rentas de sus posesiones regaladamente" 54 . Los que representan una mayor amenaza, insiste Maquiavelo, son los que "poseen castillos y tienen súbditos que les obedecen" 55 . En las provincias con tales hombres no surge "nunca ninguna república ni ningún modo de vida político"56, como es el caso de Nápoles o la Lombardía. La riqueza, cuando es excesiva, introduce una desigualdad que acaba arruinando la república. Llegado un punto, la desigualdad entre ricos y pobres es tanta que ya no es posible que las mismas leyes beneficien a todos. Cada grupo antepone sus intereses a los del común. La libertad, el vivere libero, queda amenazada por la riqueza excesiva. Maquiavelo considera que sólo es posible fundar una república allí "donde existe o se ha instituido una gran igualdad" 57 . La república es el gobierno propio de hombres libres e iguales, y para Maquiavelo no puede establecerse una república en un país donde existen señores y gentileshombres que son dueños de castillos, viven ociosos de sus rentas y tienen jurisdicción sobre otros hombres. Una cierta igualdad económica aparece como la base mínima sobre la que construir la república y son las leyes las que deben velar por mantener esas exigencias.

\footnotetext{
${ }^{53}$ Discorsi, II, 2, 225.

${ }^{54}$ Discorsi, I, 55: "Dico che gentiluomini sono chiamati quelli che oziosi vivono delle rendite delle loro possessioni abbondantemente, sanza avere cura alcuna o di coltivazione o di altra necessaria fática a vivere" (Opere, 205).

${ }^{55}$ Discorsi, I, 55: "Ma più perniziosi sono quelli che altre alle predette fortune commandano a castella, ed hanno subditi che ubbidiscono a loro" (Opere, 205). Al examinar la relación entre la riqueza y la forma de gobierno hay que tener muy en cuenta el tipo de riqueza de que se trate. No cualquier desigualdad es incompatible con la república. Por ejemplo, en Venecia, hay una importante aristocracia que controla los cargos públicos, pero su riqueza se basa en el comercio, consiste en bienes muebles, "sendo le loro ricchezze grandi fondate in sulla mercanzia e cose mobili", y por eso no es tan peligrosa como la posesión de tierras, de castillos y de súbditos, totalmente incompatible con el gobierno republicano (Ibidem, 206).

${ }^{56}$ Discorsi, I, 55, 205.

${ }^{57}$ Discorsi, I, 55: "Constituisca adunque una republica colui dove è o è fatta una grande equalità" (Opere, 207).
} 


\section{Conclusión}

Para republicanos como Maquiavelo la riqueza excesiva en manos privadas es vista con aprehensión, como una posible fuente de corrupción de la ciudad. Frente al peligro que supone la riqueza abundante de los nobles, que puede comprar clientelas, recomienda Maquiavelo empobrecer a los ciudadanos. Las repúblicas bien ordenadas deben mantener sus haciendas ricas y a sus ciudadanos pobres. Ningún grupo particular debe sobrepasar en pujanza económica a la república. Aquí el recuerdo de los banqueros florentinos, especialmente de los Médici, es evidente. La riqueza de los Médici les situaba por encima de los magistrados. Incluso aunque mantuvieran formalmente las magistraturas, su poder económico y social lo contaminaba todo ${ }^{58}$. Se habían convertido, y Maquiavelo era consciente de la contradictio in terminis, en "príncipes" de la república. Por ello no había propiamente república salvo en las formas. Para Maquiavelo, como para Catón, no se puede considerar libre a una ciudad "donde había un ciudadano al que temían los magistrados" 59 . Lo que convierte a un ciudadano en peligroso para la ciudad es que sea "riquísimo" o que tenga "allegados y partidarios"60. Una posición de privilegio, como la de los Médici en Florencia, les permitirá crear una poderosa clientela mediante los préstamos, ayudas, dotes y demás beneficios, y apoyándose en este grupo alcanzar el poder.

En el caso concreto de Maquiavelo su posición sobre la riqueza no puede separarse de su animadversión hacia los Médici, a pesar de que hizo lo que pudo por congraciarse con ellos y conseguir que le emplearan. "Sin duda, el recuerdo de los Médici estaba muy vivo al escribir las duras frases que se encuentran en su obra contra las riquezas y las desigualdades excesivas como fuentes de corrupción política"61. Aunque la Historia de Florencia fue un encargo mediceo, Maquiavelo se comportó con notable independencia de juicio y, poniendo las críticas en boca de sus enemigos, expone cómo la reputación y la molicie de esta familia adinerada sirvió de caldo de cultivo para la corrupción y para la tiranía. Cuando Maquiavelo, describe en su Historia de Florencia la

\footnotetext{
${ }^{58} \mathrm{El}$ control de las elecciones fue uno de sus principales mecanismos de poder. Véase N. RUBINSTEIN, The government of Florence under the Medici (1434 to 1494), Oxford, Oxford University Press, 1966.

${ }^{59}$ Discorsi, I, 29, 158.

${ }^{60}$ Discorsi, I, 34: "Perché gli bisogna essere ricchissimo ed avere assai aderenti e partigiani”" (Opere, 166.

${ }^{61}$ R. del ÁGUILA y S. CHAPARRO, La república de Maquiavelo, Madrid, Tecnos, 2006, 229.
} 
conjuración de los Pazzi contra Julián y Lorenzo de Médici, explica que, aparte de los errores en su ejecución, fracasó porque cuando los conjurados apelaron al pueblo de Florencia descubrieron que "al pueblo lo habían hecho sordo la fortuna y la liberalidad de los Medici"62.

La crítica de las excesivas desigualdades y los peligros de una vida ociosa son una constante del pensamiento republicano. Las ideas de Maquiavelo sobre la necesidad de moderar la riqueza fueron compartidas por otros escritores políticos del llamado republicanismo florentino como Antonio Brucioli (1498-1566) en su Della Republica, escrito en 1526, quien asegura que el solo deseo de enriquecerse descalificaría a uno para los cargos políticos y, al igual que Maquiavelo, sostiene que "in an ideal republic great differences of wealth ought not to be allowed'63. Asimismo Donato Giannotti (1492-1573) propone cierta moderación en las riquezas:

En los Estados gobernados por uno sólo se exige desigualdad, en los gobernados por la mayoría, como es nuestro caso, es necesaria la igualdad, si no de hecho, al menos de principio. Por eso es menester prohibir todo cuanto sólo los ricos pueden hacer, como los grandes gastos en ropa, banquetes y dotes a las muchachas ${ }^{64}$.

Giannotti, muy influido por Aristóteles, se inclinaría por gobiernos de clases medias. En toda sociedad hay ricos, pobres y mediocri. Y aunque todos esos diversos grupos deben ser tenidos en cuenta para gobernar, los mejores son los ciudadanos de las clases medias, únicos capaces de mandar y de ser mandados. Mientras ese grupo sea más numeroso que los otros, la ciudad se conservará estable. Y justamente eso es lo que cree Giannotti que sucede en Florencia, a saber, que se ha incrementado en importancia el grupo de los mediocri, frente a los grandi y los poveri65.

Sobre la valoración de la riqueza también se puede descubrir en Francesco Guicciardini (1483-1540) un planteamiento conforme con esta tradición republicana. Su republicanismo más aristocrático que el de Maquiavelo aparece claramente cuando

62 MAQUIAVELO, Historia de Florencia, VIII, 8, 414.

${ }^{63}$ F. GILBERT, Machiavelli and Guicciardini. Politics and History in Sixteenth-Century Florence, Princeton, New Jersey, Princeton University Press, 1965, 152.

${ }^{64}$ D. GIANNOTTI, La República de Florencia, traducción y estudio preliminar de Antonio Hermosa Andújar, presentación de Carlos Restrepo Piedrahita, Madrid, BOE, CEPC, 1997, 142 (Lib. III, cap. XVI). ${ }^{65}$ Véase J. G. A. POCOCK, The machiavellian moment. Florentine Political Thought and the Atlantic Republican Tradition, Princeton, New Jersey, Princeton University Press, 1975, 300. 
rechaza los impuestos progresivos. Al fin y al cabo, la forma de gobierno republicano que efectivamente conocieron los habitantes de Florencia en esta época tenía un fuerte sesgo aristocrático como se pone de relieve en el dato de que Soderini propuso al Gran Consejo un impuesto progresivo 106 veces y todas ellas fue rechazado ${ }^{66}$. Critica Guicciardini la corrupción y el lujo y alienta algunas medidas para que los ricos sean menos estimados de lo que lo son en su tiempo. Se puede así limitar el lujo de los vestidos que diferencian tanto al rico del pobre, evitar los malos modos de enriquecerse o reducir las dotes que a su juicio favorecen la conservación de la nobleza ${ }^{67}$. Uno de los tópicos de la tradición republicana ha sido el de que los objetos de lujo debían ser fuertemente gravados.

Así, la tradición / republicana/ fue a menudo asociada con la creencia en la oportunidad de gravar fiscalmente los bienes lujosos o suntuarios, así como con el compromiso de garantizar que no se permitiera a nadie el tipo de riqueza que pudiera hacerle capaz de corromper a los funcionarios públicos y enseñorearse de los ciudadanos menos acaudalados ${ }^{68}$.

Guicciardini comparte con Maquiavelo otro punto esencial sobre esta materia. Afirma que es más fácil, como se ve por la historia de muchos pueblos, permanecer libres en la pobreza que en la riqueza. "Guicciardini concluye su Discurso de Logroño con la observación de que, aun cuando las ciudades libres necesiten ser ricas, sus habitantes individualmente deben mantenerse pobres, sin grandes disparidades de riqueza del tipo que suele causar envidia y promover así disturbios políticos"69. Para hacer posible el vivere politico, para garantizar la libertad republicana no basta con una forma de gobierno mixto que dé cabida a todos los grupos sociales, sino que se necesita también un ejército de ciudadanos $y$, finalmente, que no haya una excesiva disparidad en la riqueza entre los ciudadanos.

\footnotetext{
${ }^{66}$ Véase "Introducción" de Stella Mastrangelo a N. MAQUIAVELO, Epistolario, 1512-1527, México, FCE, 1990, 34.

${ }^{67}$ F. GUICCIARDINI, Écrits politiques. Discours de Logroño (1512). Dialogue sur la façon de régir Florence (15211525), Introduction, traduction, postface et notes par Jean-Louis Fournel et Jean-Claude Zancarini, Paris, Presses Universitaires de France, 1997, 103.

${ }^{68}$ P. PETTIT, Republicanismo. Una teoría sobre la libertad y el gobierno, trad. de Toni Doménech, Barcelona, Paidós, 1999, 214.

${ }^{69}$ Q. SKINNER, Los fundamentos del pensamiento político moderno, I, 195.
} 